\title{
Application of Fourier Transform Infrared Spectrophotometry Method for Analysis of Metformin Hydrochloride in Marketed Tablet Dosage Form
}

\author{
Nerdy Nerdy ${ }^{1 *}$, Linda Margata ${ }^{1}$, Dian Ika Perbina Meliala ${ }^{1}$, Bunga Mari Sembiring $^{2}$, \\ Selamat Ginting ${ }^{2}$, Effendy De Lux Putra ${ }^{3}$, Atika Mulyati ${ }^{3}$, Tedy Kurniawan Bakri ${ }^{4}$ \\ ${ }^{1}$ Department of Pharmacy, Faculty of Pharmacy, Institut Kesehatan Deli Husada Deli Tua, Deli Tua Timur, Deli \\ Tua, Deli Serdang, Sumatera Utara, 20355, Indonesia \\ ${ }^{2}$ Department of Public Health, Faculty of Public Health, Institut Kesehatan Deli Husada Deli Tua, Deli Tua \\ Timur, Deli Tua, Deli Serdang, Sumatera Utara, 20355, Indonesia \\ ${ }^{3}$ Department of Pharmacy, Faculty of Pharmacy, Universitas Sumatera Utara, Padang Bulan, Medan Baru, \\ Medan, Sumatera Utara, 20155, Indonesia \\ ${ }^{4}$ Department of Pharmacy, Faculty of Mathematics and Natural Sciences, Universitas Syiah Kuala, Kopelma \\ Darussalam, Syiah Kuala, Banda Aceh, Aceh, 23111, Indonesia
}

*Corresponding author: nerdy190690@gmail.com

Received: August 2021; Revision: August 2021; Accepted: October 2021; Available online: November 2021

\begin{abstract}
The first line drug given for monotherapy for diabetes mellitus type 2 is metformin hydrochloride, which is a biguanide antihyperglycemic drug. The aim of this research was to develop, validate, and apply the Fourier Transform Infrared spectrophotometry method to identify and determine metformin hydrochloride in marketed tablet dosage form. This research included preparation of standard, analysis of samples, and validation of method. The specific wavenumber obtained for qualitative analysis was $1645.68 \mathrm{~cm}^{-1}$ and $1574.8 \mathrm{~cm}^{-1}$. The specific area obtained for quantitative analysis with a single baseline ranged from $1701.53 \mathrm{~cm}^{-1}$ to $1535.66 \mathrm{~cm}^{-1}$. All metformin hydrochloride marketed tablet dosage forms were analyzed and met all of the qualitative and quantitative requirements. The methods met the requirements of method validation for accuracy with a percentage of recovery of $100.22 \%$, precision with relative standard deviation of $0.48 \%$, linearity with a correlation coefficient of 0.9992 , limit of detection of $11.17 \mathrm{mg}$ per $\mathrm{mL}$, limit of quantitation of $33.84 \mathrm{mg}$ per $\mathrm{mL}$, and good specificity results. In this study, the Fourier Transform Infrared spectrophotometry method was successfully developed and validated for application in identification and determination of metformin hydrochloride in marketed tablet dosage form.
\end{abstract}

Keywords: Metformin hydrochloride, infrared, spectrophotometry, qualitative, quantitative.

DOI: $10.15408 / j k v \cdot v 7 i 2.22158$

\section{INTRODUCTION}

Metformin hydrochloride belongs to the biguanide group and act as an antihyperglycemic group to treat type 2 diabetes, or non-insulin dependent diabetes mellitus. Metformin hydrochloride can be used as monotherap y to decrease hepatic glucose production and increase the sensitivity of muscle tissue and as an adipose to insulin. This effect occurs due to the activation of kinase in cells (Rena et al., 2017). The most common side effects observed in patients taking metformin hydrochloride are nausea, vomiting, and diarrhea. Metformin hydrochloride is the first drug of choice for overweight patients when a strict diet fails to control diabetes mellitus (Marín-Peñalver et al., 2016). Figure 1 shows the molecular structure of metformin hydrochloride.<smiles>CN(C)C(=N)NC(=N)N</smiles>

Figure 1. The molecular structure of metformin hydrochloride 
The quality, safety, and efficacy of drugs has always been a concern of the World Health Organization, since without the guarantee that these pharmaceutical products meet the required standards of quality, safety, and effectiveness, any health service will be negatively affected (Aggarwala et al., 2019). In the manufacture of drugs, the examination of the levels of active substances is a requirement that must be met to ensure the quality, safety, and efficacy of drug preparations. Quality drug preparations will support the achievement of the desired therapeutic effect. Because of this, attention to the quality control of drugs is important (Fogel, 2018).

Several methods have been developed for the analysis of metformin hydrochloride in tablet preparation, such as: high performance liquid chromatography (Gedawy et al., 2019), ultraviolet spectrophotometry (Dange et al., 2017), and visible spectrophotometry (Ahmad, 2012). The high-performance liquid chromatography method requires expensive tools and high operational costs, as well as a relatively long analysis time (Dong, 2013). The ultraviolet spectrophotometric method is less specific for qualitative and quantitative analysis. The visible spectrophotometry method has a weakness that requires a specific reaction and limited operating time for the analysis (Adegoke, 2012).

The benefits of an alternative analytical method include but are not limited to; an easier method for preparation, a more specific means for of analysis, lower costs, faster analysis, methods that are more environmentally friendly, and can provide results with better accuracy and precision. Simultaneously qualitative and quantitative analysis by Fourier Transform Infrared has already been successfully implemented in several areas of industrial pharmacy (Marson et al., 2016). The Fourier Transform Infrared is simple, specific, cheap, fast, and a green method. The Fourier Transform Infrared can analyze any sample with little to no preparation, covers a wide range of spectrums to analyze most pharmaceutical products, and has a high resolution (Bansal et al., 2021).

As mentioned before, this method is environmentally friendly since no harmful reagents are required for the complete analysis. Determination of levels using Fourier Transform Infrared has also previously been carried out on various types of pharmaceutical ingredients, such as determining levels of mineral drugs (Ouhaddouch et al., 2019), hypertension drugs (Padmavathi et al., 2020), and cholesterol drugs (Mounika et al., 2018). The researchers were interested in applying metformin hydrochloride analysis on marketed tablet dosages form with a developed and validated Fourier Transform Infrared spectrophotometry method with methanol as a solvent.

\section{MATERIALS AND METHODS Research}

This research is a kind of descriptive research using the Fourier Transform Infrared spectrophotometry method to identify and determine the level of metformin hydrochloride contained in marketed tablet dosages. The method used in this research included preparation of standard, analysis of sample, and validation of method with a slight modification from previous research (Robaina et al., 2013).

\section{Tools}

The tools used in this study was a set of Fourier Transform Infrared for light source, interferometer, detector (Agilent - Cary 630 Series), Computer (Lenovo - V530 Series), Printer (Epson - L550 Series), analytical balance (Radwag - X2 Series), multipette (Eppendorf - E3X Series), sonicator (Krisbow PS40A Series), mortar and pestle (Medstuff), filter paper (Whatman), tissue (Paseo), and glassware (Iwaki).

\section{Materials}

The materials used in this study were methanol (Merck), and metformin hydrochloride standard (Merck).

\section{Sample}

The samples used in this study were Diabit $^{\circledR}$ tablets (PT. Hexpharm Jaya), Eraphage $^{\circledR}$ tablets (PT. Guardian Pharmatama), Glikos ${ }^{\circledR}$ tablets (PT. Ifars), Glucophage $^{\circledR}$ tablets (PT. Merck), Gludepatic ${ }^{\circledR}$ tablets (PT. Pratapa Nirmala), Metformin Hydrochloride tablets (PT. Bernofarm), Metformin Hydrochloride tablets (PT. Dexa Medica), and Metformin Hydrochloride tablets (PT. Hexpharm Jaya). 


\section{Preparation of Standard}

A standard stock of metformin hydrochloride solution was prepared with a weight of $5 \mathrm{~g}$, which was then dissolved in 50 $\mathrm{mL}$ of methanol to obtain a standard stock solution with a concentration of $100 \mathrm{mg}$ per $\mathrm{mL}$. Standard solution was prepared by diluting $5 \mathrm{~mL}$ standard stock solution with 10 $\mathrm{mL}$ methanol to obtain a stock solution with a concentration of $50 \mathrm{mg}$ per $\mathrm{mL}$. The vibration spectrum of standard solution and methanol (as blank) were separately measured at wavenumbers ranging from $4000 \mathrm{~cm}^{-1}$ to 650 $\mathrm{cm}^{-1}$. The specific wavenumber of metformin hydrochloride was obtained from overlay between vibration spectrums of standard solution and the methanol used for qualitative analysis. Each measurement was replicated six times. Standard series solutions were prepared by separately diluting $3 \mathrm{~mL}, 4 \mathrm{~mL}, 5 \mathrm{~mL}, 6$ $\mathrm{mL}$, and $7 \mathrm{~mL}$ of standard stock solution with $10 \mathrm{~mL}$ of methanol to obtainstock solutions with concentrations of $30 \mathrm{mg}$ per $\mathrm{mL}, 40 \mathrm{mg}$ per $\mathrm{mL}, 50 \mathrm{mg}$ per $\mathrm{mL}, 60, \mathrm{mg}$ per $\mathrm{mL}$, and $70 \mathrm{mg}$ per $\mathrm{mL}$. The series vibration spectra of standard series solutions and methanol (as blank) were separately measured at wavenumbers ranging from $4000 \mathrm{~cm}^{-1}$ to 650 $\mathrm{cm}^{-1}$. The area for a specific wavenumber was obtained and calculated with the determination coefficient $\left(\mathrm{R}^{2}\right)$, slope (a), intercept (b), and regression equation $(Y=a \times X+b)$ used for quantitative analysis. Each measurement was replicated six times.

\section{Analysis of Sample}

A sample solution was prepared using 20 powdered tabletsand weighed. The powder was weighed out to $500 \mathrm{mg}$ of metformin hydrochloride, and then dissolved in $10 \mathrm{~mL}$ of methanol to obtain a sample solution with a theoretical concentration of $50 \mathrm{mg}$ per $\mathrm{mL}$. The vibration spectrum of the sample solution and methanol (as blank) were separately measured at wavenumbers ranging from 4000 $\mathrm{cm}^{-1}$ to $650 \mathrm{~cm}^{-1}$. The specific wavenumber of metformin hydrochloride was obtained from overlay between the vibration spectrum of standard solution and the methanol used for qualitative analysis. The areas for specific wavenumbers were obtained and used for quantitative analysis (calculating the concentration by regression equation obtained from standard series solutions). Each measurement was replicated six times.

\section{Validation of Method}

Accuracy was tested by measuring the percentage of recovery with the standard addition method in three specific ranges, namely: $80 \%, 100 \%$ and $120 \%$.Each specific range contained $70 \%$ of the analyzed samples (samples with levels of metformin hydrochloride closest to $100 \%$ ) and $30 \%$ standard added. Precision was calculated using the relative standard deviation, based on the percentage of recovery obtained from the accuracy test. Linearity was analyzed by calculating the coefficient of correlation (R) based on data obtained from the standard series solutions measurement. The limit of detection and limit of quantitation were calculated based on data obtained from the standard series solutions measurement. The specificity was analyzed from the samples analysis results.

\section{RESULTS AND DISCUSSION Maximum Vibration Spectrum Determination Results}

This research begins with the measurement of the vibrational spectrum of methanol as a blank. The vibration spectrum of methanol can be seen in Figure 2.

The research continued with the measurement of the vibrational spectrum of metformin hydrochloride standard solution in methanol with a concentration of $50 \mathrm{mg}$ per $\mathrm{mL}$. The vibration spectrum of metformin hydrochloride standard solution in methanol (concentration of $50 \mathrm{mg}$ per $\mathrm{mL}$ ) can be seen in Figure 3.

After obtaining the vibration spectrum of methanol and the vibration spectrum of metformin hydrochloride standard solution in methanol with concentrations of $50 \mathrm{mg}$ per $\mathrm{mL}$; an overlay was carried out to determine the specific wavenumber of metformin hydrochloride for qualitative analysis and quantitative analysis. The overlay between the vibration spectrum of methanol and the vibration spectrum of metformin hydrochloride standard solution in methanol (concentration of $50 \mathrm{mg}$ per $\mathrm{mL}$ ) can be seen in Figure 4.

Overlay results show that there was a significant difference between the vibration spectrum of methanol and the vibration spectrum of metformin hydrochloride standard solution in methanol (concentration of $50 \mathrm{mg}$ per $\mathrm{mL}$ ). Significant spectrum differences can be seen between wavenumbers $1500 \mathrm{~cm}^{-1}$ to 
$1700 \mathrm{~cm}^{-1}$, which is $1645.68 \mathrm{~cm}^{-1}$ and 1574.84 $\mathrm{cm}^{-1}$. Strong absorbance on the metformin hydrochloride spectrum was observed between wavenumbers $1500 \mathrm{~cm}^{-1}$ to $1700 \mathrm{~cm}^{-1}$ (Ramalingam et al., 2014). These wavenumbers are specific wavenumbers that are owned by metformin hydrochloride and not owned by methanol, so a qualitative analysis can be performed on these wavenumbers. A good region for qualitative analysis and quantitative analysis was the fingerprint region between wavenumbers $1500 \mathrm{~cm}^{-1}$ to $1800 \mathrm{~cm}^{-1}$ (Mata-Miranda et al., 2019).
Quantitative analysis was carried out using the peak area at specific wavenumbers of metformin hydrochloride, namely 1645.68 $\mathrm{cm}^{-1}$ and $1574.8 \mathrm{~cm}^{-1}$. The results of the observation of the peak area at a specific wavenumber determined that the peak analysis was carried out with a single baseline start wavenumber of $1701.53 \mathrm{~cm}^{-1}$ and a baseline end wavenumber of $1535.66 \mathrm{~cm}^{-1}$. The peak area obtained can be used for quantitative analysis of metformin hydrochloride. The peak area determination of the vibration spectrum of metformin hydrochloride standard solution in methanol (concentration of $50 \mathrm{mg}$ per $\mathrm{mL}$ ) can be seen in Figure 5.

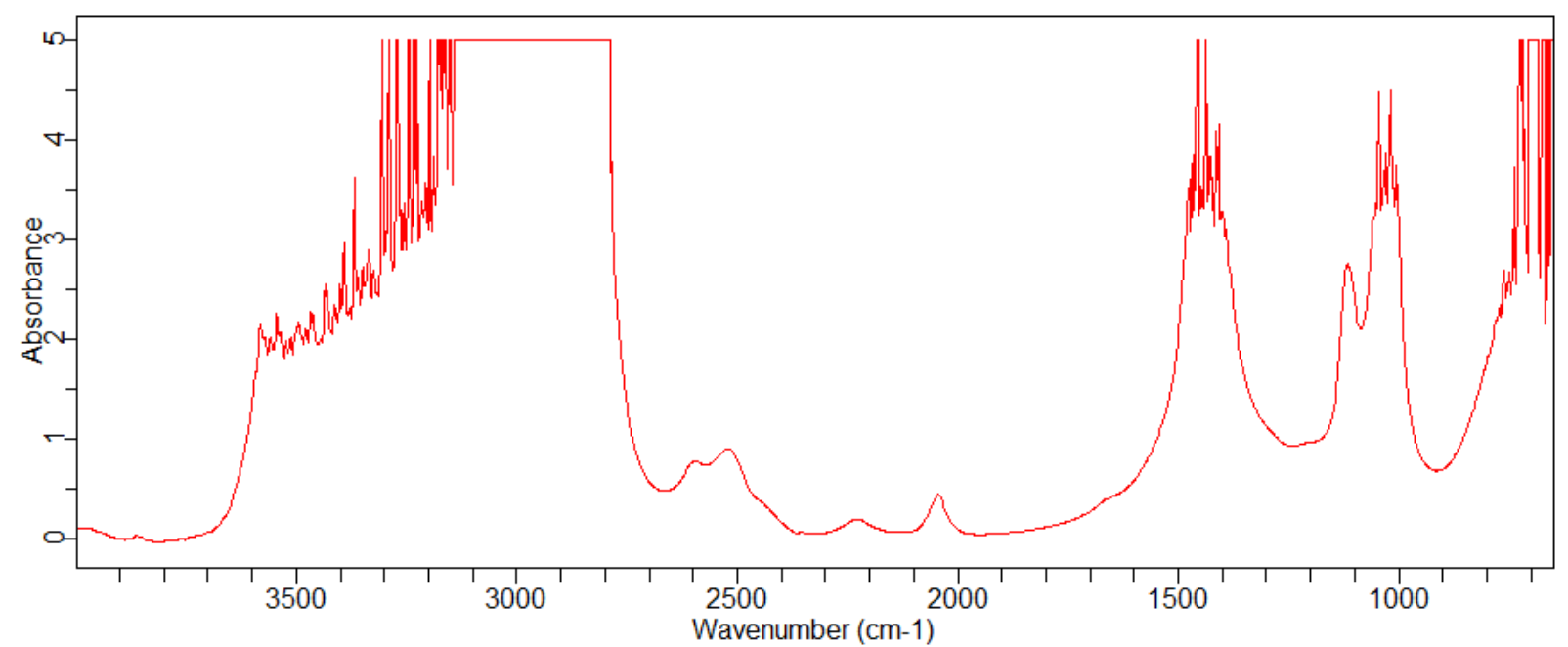

Figure 2. The vibration spectrum of methanol

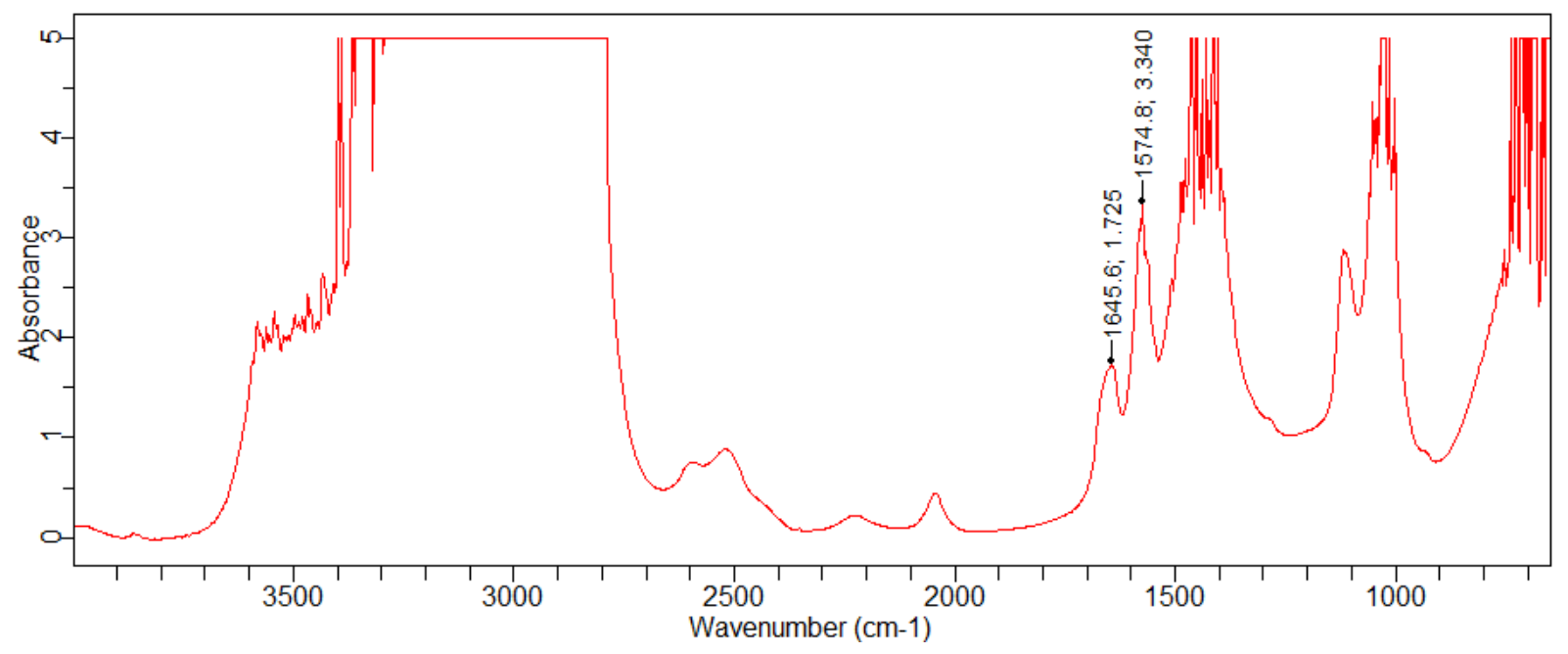

Figure 3. The vibration spectrum of metformin hydrochloride standard solution in methanol (concentration of $50 \mathrm{mg}$ per $\mathrm{mL}$ ) 


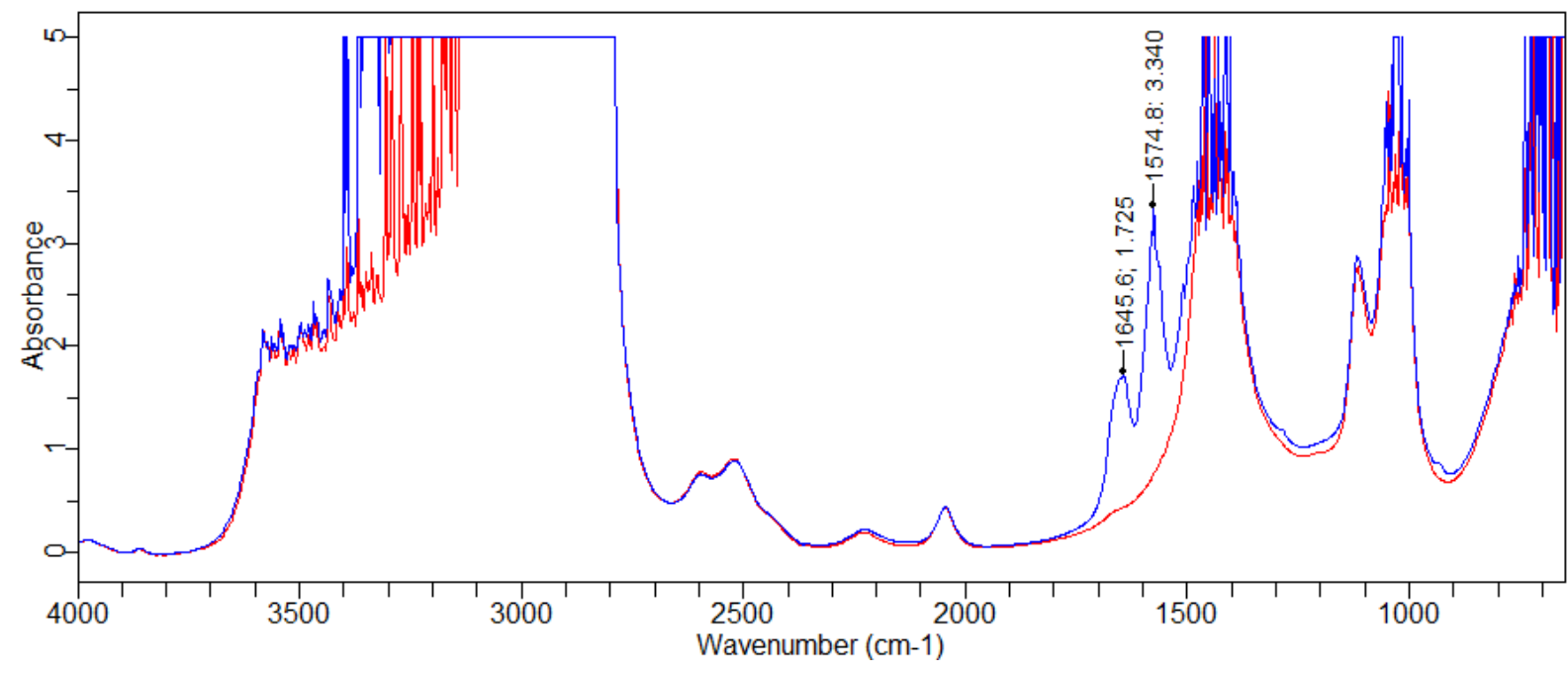

Figure 4. The overlay between vibration spectrum of methanol (red line) and vibration spectrum of metformin hydrochloride standard solution in methanol (concentration of $50 \mathrm{mg}$ per $\mathrm{mL}$ ) (blue line)

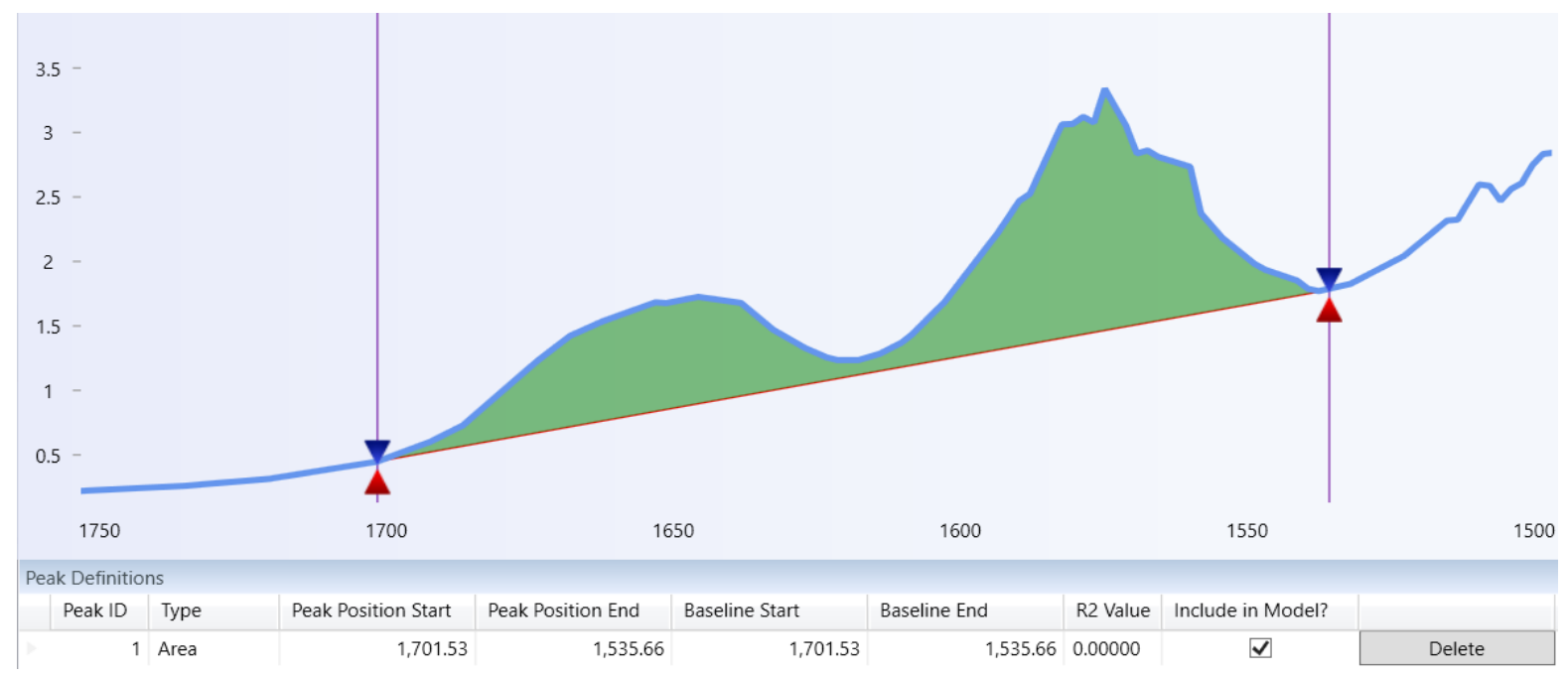

Figure 5. The peak area determination of the vibration spectrum of metformin hydrochloride standard solution in methanol (concentration of $50 \mathrm{mg}$ per $\mathrm{mL}$ )

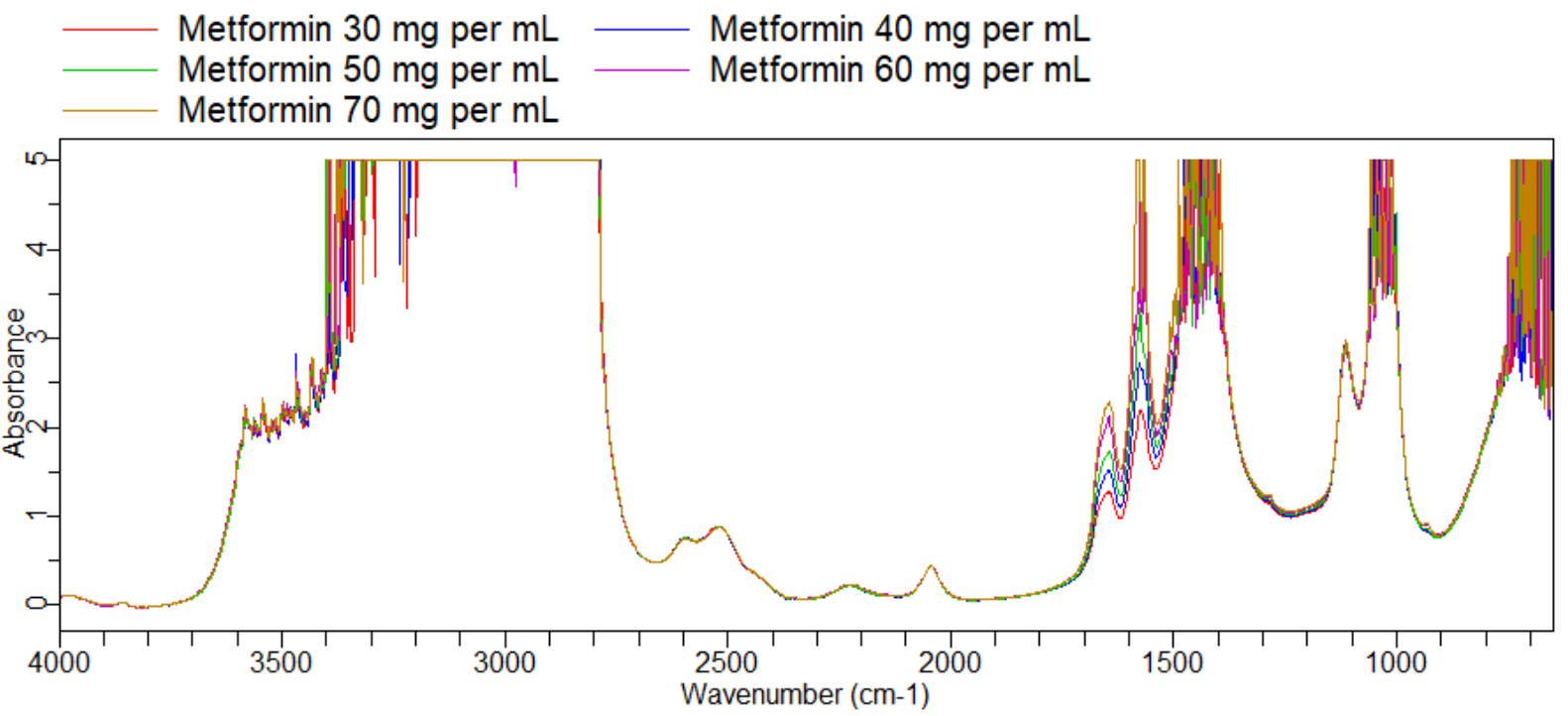

Figure 6. The overlay of series vibration spectra of metformin hydrochloride standard series solutions in methanol (30 $\mathrm{mg}$ per $\mathrm{mL}$ to $70 \mathrm{mg}$ per $\mathrm{mL}$ ) 
Table 1. The peak area data of metformin hydrochloride standard series solutions in methanol (30 $\mathrm{mg}$ per $\mathrm{mL}$ to $70 \mathrm{mg}$ per $\mathrm{mL}$ )

\begin{tabular}{ccc}
\hline Number & $\begin{array}{c}\text { X - Concentration } \\
\text { (mg per mL) }\end{array}$ & $\begin{array}{c}\text { Y - Peak } \\
\text { Area (AU) }\end{array}$ \\
\hline 1. & 30 & 188.41 \\
2. & 40 & 227.18 \\
3. & 50 & 272.55 \\
4. & 60 & 312.62 \\
5. & 70 & 361.80 \\
\hline
\end{tabular}

Prior to quantitative analysis, a regression equation was determined which was used for quantitative calculation of the concentration and levels of metformin hydrochloride in the marketed tablet dosage form. The regression equation was obtained by measuring metformin hydrochloride standard series solutions in methanol with concentrations ranging from $30 \mathrm{mg}$ per $\mathrm{mL}$ to $70 \mathrm{mg}$ per $\mathrm{mL}$. The overlay of series vibration spectra of metformin hydrochloride standard series solutions in methanol $(30 \mathrm{mg}$ per $\mathrm{mL}$ to $70 \mathrm{mg}$ per $\mathrm{mL}$ ) can be seen in Figure 6. The peak area data of metformin hydrochloride standard series solutions in methanol $(30 \mathrm{mg}$ per $\mathrm{mL}$ to $70 \mathrm{mg}$ per $\mathrm{mL}$ ) can be seen in Table 1. The calibration curve of metformin hydrochloride standard series solutions in methanol (30 mg per $\mathrm{mL}$ to $70 \mathrm{mg}$ per $\mathrm{mL}$ ) can be seen in Figure 7.

The metformin hydrochloride series vibrational spectra at various concentrations of metformin hydrochloride in methanol shows that the concentrations do not change the spectrum shape of each concentration on $1645.68 \mathrm{~cm}^{-1}$ and $1574.84 \mathrm{~cm}^{-1}$, which means the use of methanol as a solvent is stable against metformin hydrochloride (Benmessaoud et al., 2016). From these results it can be seen that the higher the measured concentration is, the greater the peak area will be. The coefficient of determination obtained was 0.9985 with a regression equation of $\mathrm{Y}=4.3221 \times \mathrm{X}+$ 56.4045. The determination coefficient obtained was appropriate with values more than 0.99 , which indicated that the peak area ( $\mathrm{Y}$ or ordinate) can be used for determination of concentration (X or abcis) (Kuete et al., 2020).

Determination of the levels of metformin hydrochloride was carried out by Fourier Transform Infrared spectrophotometry with peak area analysis. The peak area obtained was used to calculate the concentration based on the regression equation and finalized with the level of metformin hydrochloride calculation. The data related to metformin levels in marketed tablet dosage form can be seen in Table 2 .

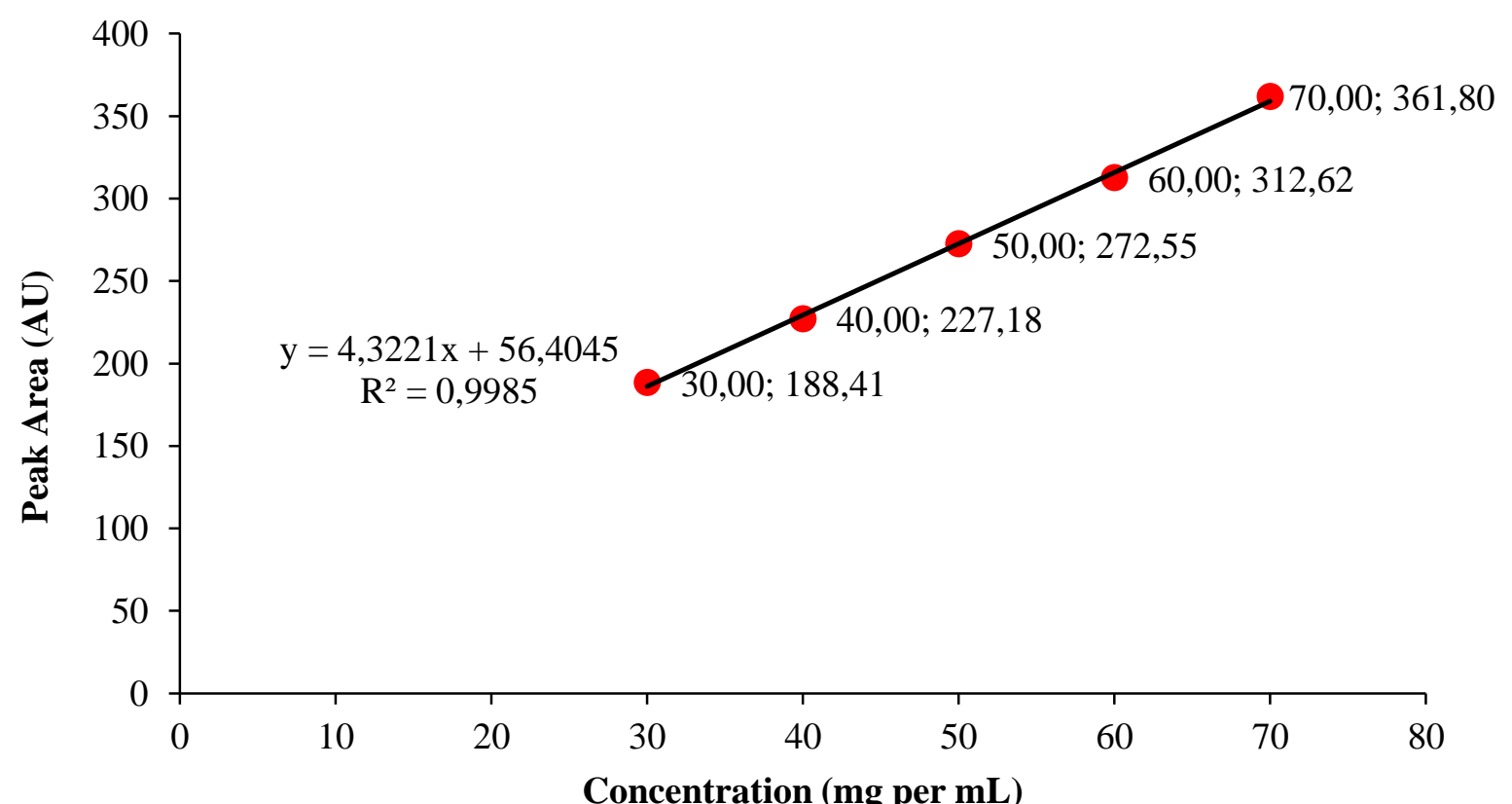

Figure 7. The calibration curve of metformin hydrochloride standard series solutions in methanol (30 mg per $\mathrm{mL}$ to $70 \mathrm{mg}$ per $\mathrm{mL}$ ) 
Table 2. The metfomin levels data in marketed tablet dosage form

\begin{tabular}{ccc}
\hline Number & Sample & Level of Metformin Hydrochloride \\
\hline 1 & Diabit $^{\circledR}$ (PT. Hexpharm Jaya) & $98.59 \% \pm 0.17 \%$ \\
2 & ${\text { Eraphage }{ }^{\circledR} \text { (PT. Guardian Pharmatama) }}^{{ }^{\circledR}}$ & $102.79 \% \pm 0.22 \%$ \\
3 & Glikos $^{\circledR}$ (PT. Ifars) & $98.73 \% \pm 0.22 \%$ \\
4 & Glucophage $^{\circledR}$ (PT. Merck) & $101.74 \% \pm 0.27 \%$ \\
5 & Gludepatic $^{\circledR}$ (PT. Pratapa Nirmala) & $99.40 \% \pm 0.19 \%$ \\
6 & Metformin Hydrochloride (PT. Bernofarm) & $97.51 \% \pm 0.20 \%$ \\
7 & Metformin Hydrochloride (PT. Dexa Medica) & $99.67 \% \pm 0.21 \%$ \\
8 & Metformin Hydrochloride (PT. Hexpharm Jaya) & $101.53 \% \pm 0.24 \%$ \\
\hline
\end{tabular}

Table 3. The validation data of the Fourier Transform Infrared spectrophotometry method

\begin{tabular}{ccc}
\hline Number & Category & Results \\
\hline 1 & Percentage of Recovery for $80 \%$ Specific Range & $100.19 \%$ \\
2 & $(40 \mathrm{mg}$ per mL) & $100.33 \%$ \\
3 & & $100.26 \%$ \\
4 & Percentage of Recovery for 100 \% Specific Range & $100.83 \%$ \\
5 & $(50 \mathrm{mg}$ per mL) & $100.75 \%$ \\
6 & & $100.67 \%$ \\
8 & Percentage of Recovery for 120 \% Specific Range & $99.75 \%$ \\
9 & $(60$ mg per mL) & $99.54 \%$ \\
- & Accuracy (Percentage of Recovery) & $99.65 \%$ \\
- & Precision (Relative Standards Deviation) & $100.22 \%$ \\
- & Linearity (Coefficient of Correlation) & $0.48 \%$ \\
- & Limit of Detection & 0.9992 \\
\hline
\end{tabular}

The results indicate that metformin hydrochloride levels in marketed tablet dosage form range from $97.51 \%$ to $102.79 \%$ which meet the requirements of the monograph. The metformin hydrochloride tablet dosage form is in accordance with the requirements listed in the Indonesian Pharmacopoeia, $6^{\text {th }}$ edition, year 2020; which detailed metformin hydrochloride tablets that contained levels of metformin hydrochloride that were not under $95.0 \%$ and not more than $105.0 \%$ of the amount stated on the label (Ministry of Health Republic of Indonesia, 2020). It is important that drug preparations contain appropriate levels of active substances as one of the main parameters to ensure that a drug meets the requirements for quality, safety, and efficacy (Seo et al., 2020). The Fourier Transform Infrared spectrophotometry method is a useful tool that can be used to prove the validity of results for qualitative and quantitative analysis (Mendes and Duerte, 2021). The validation data of the Fourier Transform Infrared spectrophotometry method can be seen in Table 3.

The accuracy of the method met the accuracy requirements for method validation with a range recovery percentage of $98 \%$ to $102 \%$ (Pinto et al., 2017). The precision of the method was met with the precision requirements for method validation with a relative standard deviation of less than $2 \%$ (Assali et al., 2020). The linearity of the method met the linearity requirements for method validation with a correlation coefficient of no less than 0.99 (Shaikh and Jadhav, 2020). The limit of detection and limit of quantitation obtained were $11.17 \mathrm{mg}$ per $\mathrm{mL}$ and $33.84 \mathrm{mg}$ per $\mathrm{mL}$ repectively. The detection limit and quantitation limit obtained were lower than the expected concentrations for identification and determination of the levels of metformin hydrochloride in marketed tablet dosage form. The results indicated that the method has adequate sensitivity (Sengul, 2016). The range of the developed Fourier 
Transform Infrared spectrophotometry method was $40 \mathrm{mg}$ per $\mathrm{mL}$ to $60 \mathrm{mg}$ per $\mathrm{mL}$, which was $80 \%$ from the targeted concentration to $120 \%$ of the targeted concentration. The range must cover all the accuracy, precision, linearity, limit of detection, and limit of quantitation (Marson et al., 2020). The developed method also successfully identified and determined all the metformin hydrochloride in marketed tablet dosage form, which means this method could also be applied to other tablet matrixes.This proves that the method possesses a high level of specificity (Ramakrishna et al., 2020).

\section{CONCLUSION}

The Fourier Transform Infrared spectrophotometry method has been successfully developed and validated for identification and determination of metformin hydrochloride in marketed tablet dosage form. All the metformin hydrochloride in marketed tablet dosage form met the requirements for qualitative analysis and quantitative analysis. The method also met the requirements of method validation for accuracy, precision, linearity, limit of detection, limit of quantitation, range, and specificity.

\section{ACKNOWLEDGMENT}

The authors would like to acknowledge the Institut Kesehatan Deli Husada Deli Tua for their financial support and Mutiara Mukti Farma Industri Farmasi for tools and materials support.

\section{REFERENCES}

Adegoke OA. 2012. Chemical Derivatization Methodologies for UV-Visible Spectrophotometric Determination of Pharmaceuticals. International Journal of Pharmaceutical Sciences Review and Research. 14(2): 6-24.

Aggarwala A, Aeranb H, and Rathee M. 2019. Quality Management in Healthcare: The Pivotal Desideratum. Journal of Oral Biology and Craniofacial Research. 9(2): 180-182.

DOI: 10.1016/j.jobcr.2018.06.006

Ahmad NR. 2012. Facial Visible Spectrophotometric Determination of Metformin Hydrochloride in Glucosam Tablets and Industrial Waste Water:
Application to Content Uniformity Testing. Iraqi Journal Pharmacy. 12(1): 75-85. DOI: 10.33899/iphr.2012.62346

Assali M, Abualhasan M, Zohud N, and Ghazal N. 2020. RP-HPLC Method Development and Validation of Synthesized Codrug in Combination with Indomethacin, Paracetamol, and Famotidine. International Journal of Analytical Chemistry. 2020; 2020 (7): 1894907. DOI: $10.1155 / 2020 / 1894907$

Bansal R, Singh R, and Kaur K. 2021. Quantitative Analysis of Doxorubicin Hydrochloride and Arterolane Maleate by Mid IR Spectroscopy Using Transmission and Refectance Modes. BMC Chemistry. 15(1): 27. DOI: 10.1186/s13065-021-00752-3

Benmessaoud I, Koutchoukali O, Bouhelassa M, Nouar A, and Veesler S. 2016. Solvent Screening and Crystal Habit of Metformin Hydrochloride. Journal of Crystal Growth. 451(7): 42-51. DOI: 10.1016/j.jcrysgro.2016.07.001

Dange YD, Honmane SM, Bhinge SD, Salunkhe VR, Jadge DR. 2017. Development and Validation of UV-Spectrophotometric Method for Estimation of Metformin in Bulk and Tablet Dosage Form. Indian Journal of Pharmaceutical Education and Research. 51(4S): S754-S760. DOI: 10.5530/ijper.51.4s.109

Dong MW. 2013. The Essence of Modern HPLC: Advantages, Limitations, Fundamentals, and Opportunities. LCGC North America. 31(6): 472-479.

Fogel DB. 2018. Factors Associated with Clinical Trials that Fail and Opportunities for Improving the Likelihood of Success: A Review. Contemporary Clinical Trials Communications. 11(8): 156-164. DOI: 10.1016/j.conctc.2018.08.001

Gedawy A, Al-Salami H, and Dass CR. 2019. Development and Validation of a New Analytical HPLC Method for Simultaneous Determination of the Antidiabetic Drugs, Metformin and Gliclazide. Journal of Food Drug Analysis. 27(7): $\quad 315-322$.

10.1016/j.jfda.2018.06.007

Kuete I, Tchuifon D, Ndifor-Angwafor G, Kamdem A, and Anagho S. 2020. Kinetic, Isotherm and Thermodynamic Studies of the 
Adsorption of Thymol Blue onto Powdered Activated Carbons from Garcinia cola Nut Shells Impregnated with $\mathrm{H}_{3} \mathrm{PO}_{4}$ and $\mathrm{KOH}$ : Non-Linear Regression Analysis. Journal of Encapsulation and Adsorption Sciences. 10(3): 1-27. DOI: 10.4236/jeas.2020.101001

Marín-Peñalver JJ, Martín-Timón I, SevillanoCollantes C, and del Cañizo-Gómez FJ. 2017. Update on the Treatment of Type 2 Diabetes Mellitus. World Journal of Diabetes. 7(17): 354-395. DOI: 10.4239/wjd.v7.i17.354

Marson BM, Concentino V, Junkert AM, Fachi MM, Vilhena RO, and Pontarolo R. 2020. Validation of Analytical Methods in A Pharmaceutical Quality System: An Overview Focused on HPLC Methods. Quimica Nova. 43(8): 1190-1203. DOI: 10.21577/0100-4042.20170589

Marson BM, de Oliveira Vilhena R, de Souza Madeira CR, Pontes FLD, Piantavini MS, and Pontarolo R. 2016. Simultaneous Quantification of Artesunate and Mefloquine in Fixed-Dose Combination Tablets by Multivariate Calibration with Middle Infrared Spectroscopy and Partial Least Squares Regression. Malaria Journal. 15(1):109. DOI: 10.1186/s12936016-1157-1

Mata-Miranda MM, Guerrero-Ruiz M, GonzalezFuentes JR, Hernandez-Toscano CM, Garcia-Andino JR, Sanchez-Brito M, and Vazquez-Zapien 2019. Characterization of the Biological Fingerprint and Identification of Associated Parameters in Stress Fractures by FTIR Spectroscopy. BioMed Research International. 2019(9): 1241452. DOI: $10.1155 / 2019 / 1241452$

Mendes E, and Duarte N. 2021. Mid-Infrared Spectroscopy as a Valuable Tool to Tackle Food Analysis: A Literature Review on Coffee, Dairies, Honey, Olive Oil and Wine. Foods. 10(2): 477. DOI: 10.3390/foods 10020477

Ministry of Health Republic of Indonesia. Indonesian Pharmacopoeia. $6^{\text {th }}$ Edition. 2020: Indonesia. Jakarta. 1130-1132

Mounika P, Padmavathi Y, Anjali A, and Reddy NP. 2018. Quantitative Estimation of Atorvastatin Calcium in Bulk and Tablet Dosage Forms Using FTIR Spectroscopy.
International Journal of Pharma and Bio Sciences. 9(2): 221-232. DOI: 10.22376/ijpbs.2018.9.2.p221-232

Ouhaddouch H, Cheikh A, Idrissi MOB, Draoui M, and Bouatia M. 2019. FT-IR Spectroscopy Applied for Identification of a Mineral Drug Substance in Drug Products: Application to Bentonite. Journal of Sepctroscopy. 2019(3): 2960845. DOI: $10.1155 / 2019 / 2960845$

Padmavathi Y, Chilka R, and Tummala R. 2020. Development and Validation of FTIR Spectroscopic Method for Simultaneous Estimation of Telmisartan and Hydrochlorothiazide in Pure and Pharmaceutical Dosage Forms. International Journal of Pharmaceutical Sciences and Research. 11(2): 862-872. DOI: $\quad$ 10.13040/IJPSR.09758232.11(2).862-72

Pinto IC, Cerqueira-Coutinho C, de Freitas ZMF, dos Santos EP, do Carmo FA, Junior ER. 2017. Development and validation of an analytical method using High Performance Liquid Chromatography (HPLC) to determine ethyl butylacetylaminopropionate in topical repellent formulations. Brazilian Journal of Pharmaceutical Sciences. 2017; 53(2):e16033. DOI: 10.1590/s217597902017000216033

Ramakrishna UV, Shyam SR, Rajesh KK, Sukesh NS. 2020. Method development and validation for rapid identification of epigallocatechin gallate using ultra-high performance liquid chromatography. Plos One. 15(1): e0227569. DOI: 10.1371/journal.pone.0227569

Ramalingam P, Reddy YP, Kumar KV, Chandu BR, and Rajendran K. 2014. Evaluation of Metformin Hydrochloride in Wistar Rats by FTIR-ATR Spectroscopy: A Convenient Tool in the Clinical Study of Diabetes. Journal of Natural Science, Biology and Medicine. 5(2): 288-292. DOI: $10.4103 / 0976-9668.136168$

Rena G, Hardie DG, and Pearson ER. 2017. The Mechanisms of Action of Metformin. Diabetologia. 60(8): 1577-1585. DOI 10.1007/s00125-017-4342-z

Robaina NF, de Paula CER, Brum DM, de la Guardia M, Garrigues S, Cassella RJ. 2013. Novel Approach for the 
Determination of Azithromycin in Pharmaceutical Formulations by Fourier Transform Infrared Spectroscopy in Film through Transmission Mode. Microchemical Journal. 110(5): 301-307. DOI: $10.1016 /$ j.microc.2013.04.015

Sengul U. 2016. Comparing determination methods of detection and quantification limits for aflatoxin analysis in hazelnut. Journal of Food Drug Analysis. 24(5): 56-62.

Seo KS, Bajracharya R, Lee SH, and Han HK.

2020. Pharmaceutical Application of
Tablet Film Coating. Pharmaceutics. 12(9): $853 . \quad$ DOI: 10.3390/pharmaceutics 12090853

Shaikh M, and Jadhav AP. Development and Validation of RP-HPLC Method for Simultaneous Estimation of Gallic Acid, Curcumin and Piperine in an Ayurvedic Formulation. International Journal of Pharmacy and Pharmaceutical Sciences. 12(6): $\quad 81-86$.

10.22159/ijpps.2020v12i6.33801

DOI: 